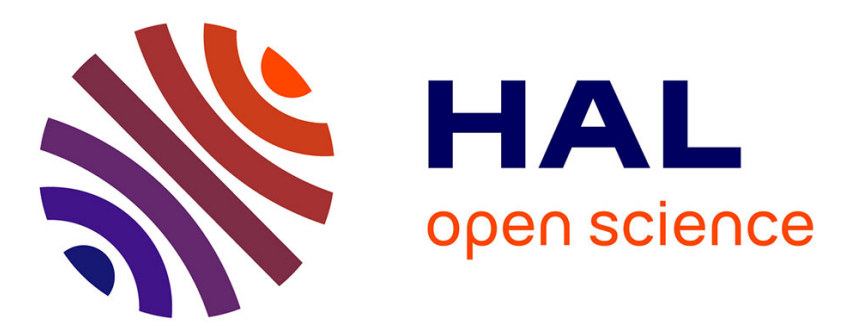

\title{
Hybrid Evaluatives: In Defense of a Presuppositional Account
}

Bianca Cepollaro, Isidora Stojanovic

\section{To cite this version:}

Bianca Cepollaro, Isidora Stojanovic. Hybrid Evaluatives: In Defense of a Presuppositional Account. Grazer Philosophische Studien - Internationale Zeitschrift für Analytische Philosophie, 2016, 93 (3), pp.458-488. 10.1163/18756735-09303007 . hal-02142057

\section{HAL Id: hal-02142057 https://hal.science/hal-02142057}

Submitted on 28 May 2019

HAL is a multi-disciplinary open access archive for the deposit and dissemination of scientific research documents, whether they are published or not. The documents may come from teaching and research institutions in France or abroad, or from public or private research centers.
L'archive ouverte pluridisciplinaire HAL, est destinée au dépôt et à la diffusion de documents scientifiques de niveau recherche, publiés ou non, émanant des établissements d'enseignement et de recherche français ou étrangers, des laboratoires publics ou privés. 


\title{
Hybrid Evaluatives
}

\section{in defense of a presuppositional account}

\author{
Bianca Cepollaro \\ Scuola Normale Superiore \& Institut Jean Nicod, ENS \\ bianca.cepollaro@gmail.com \\ Isidora Stojanovic \\ Institut Jean Nicod, DEC, ENS, CNRS, PSL Research University \\ isidora.stojanovic.nicod@gmail.com
}

This is an earlier draft of Cepollaro, B. and Stojanovic, I. (2016),

"Hybrid Evaluatives: In Defense of a Presuppositional Account",

Grazer Philosophiesche Studien 93: 458-488.

Please refer to the published version for any citation.

\begin{abstract}
In this paper, we present a presuppositional account for a class of evaluative terms that encode both a descriptive and an evaluative component: slurs and thick terms. We discuss several issues related to the hybrid nature of these terms, such as their projective behavior, the ways in which one may reject their evaluative content, and the ways in which evaluative content is entailed or implicated (as the case may be) by the use of such terms.
\end{abstract}

Keywords. slurs, thick terms, presupposition, evaluative predicates, expressive content, multidimensional adjectives

\section{Introduction}

Our aim is to present a unified account of two classes of terms that have caught the attention of scholars in philosophy of language, linguistics and metaethics: slurs and thick terms. This interest is due to the hybrid nature of these terms, as they are believed to encode a descriptive and an evaluative 
component at the same time. We shall thus use the term "hybrid evaluative" as a general term that covers both slurs and thick terms, leaving it open which other sorts of expression (if any) may count as hybrid evaluatives. ${ }^{1}$ The unified account of thick terms and slurs that we propose relies on the idea that both classes of expressions trigger a certain kind of evaluative presupposition. In a nutshell, our proposal is that both types of hybrid evaluatives are descriptive at the level of truth-conditions, but presuppose an evaluative content. Thus, for example, the adjective 'lewd' has roughly the same truth-conditional content as "sexually explicit", but at the same time it triggers the presupposition that things that are sexually explicit are bad (because of being sexually explicit). Along similar lines, we argue that a slur such as 'wop' has the same truthconditions as 'Italian' but at the same time triggers the presupposition that Italians are bad (because of being Italian).

On this approach, slurs appear to be very similar to a particular kind of thick terms, the so-called 'objectionable' thick terms. Many authors (Eklund 2011, Väyrynen 2013, Kyle 2013) distinguish between objectionable and nonobjectionable thick terms: in the former cases speakers are willing to accept the conveyed evaluation as appropriate; in the latter, they are not Note that this feature - being objectionable or not - is completely independent from the evaluation being negative or positive: for example a speaker may well share the negative evaluation conveyed by 'brutal', but reject the one conveyed by 'lewd' and, on the other hand, share the positive evaluation conveyed by 'generous, but reject the one conveyed by 'chaste'. Unlike the polarity of the evaluation, the objectionable - non-objectionable distinction is not lexically encoded, but depends on the sets of values endorsed by individual speakers. In the above examples ('lewd', 'brutal', 'chaste', 'generous'), the values called into

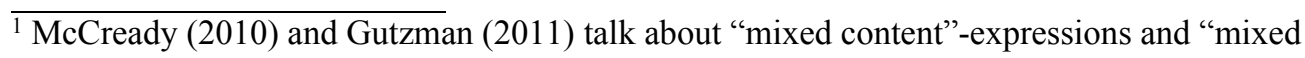
expressive" to refer to terms that contribute descriptive content at the at-issue dimension, but at the same time they contribute expressive content at the conventional-implicature level. According to them, expressive content is always speaker-directed, i.e. it is about the speaker's attitude. 
play are moral values ${ }^{2}$. The moral dimension, though, however central, is not the only relevant dimension for hybrid evaluatives: other kinds of values might be called into play as well, such as aesthetic values, as in the case of 'balanced' or 'graceful' (Sibley 1959). Moreover, there is some dispute whether terms like 'painful' and 'disgusting' should count as thick. These terms appear to call into play a sensory and an emotional dimension, rather than depend on a set of values. Our suggestion is that their descriptive content refers to sensory states that are prototypically negative (mutatis mutandis for positive terms such as 'enjoyable'). Given that the use of such terms is indeed systematically associated to an evaluation, we consider them to belong among hybrid evaluatives, and we aim our account to apply to them, too. This being said, our focus in this paper will be on value-based thick terms.

The paper is structured as follows. In section 2, we propose a criterion to distinguish between hybrid evaluatives from words that, in certain contexts, may be used evaluatively, and we discuss the differences between thin and thick terms. In section 3, we show systematic analogies between the linguistic behavior of slurs and thick terms, in particular as regards the projection of their evaluative content and the strategies employed to reject the descriptive and the evaluative content respectively. Section 4 explores at greater length the semantic features of the account that we propose. We argue that the allpurpose evaluatives 'good' and 'bad', which figure in the presuppositions triggered by hybrid evaluatives, are highly context-sensitive. We also show how the meaning of thick terms helps to narrow down the available interpretations of the associated evaluative presuppositions, and how slurs work somewhat differently in that respect. In section 5, we discuss some objections voiced against the presuppositional accounts of slurs and thick terms respectively. In the case of slurs, the main issue concerns local

2 It is reasonable to say that the same goes for slurs as well. There is a certain agreement among scholars about slurs expressing contempt. If we grant that contempt pertains to the moral dimension, then we can hold that slurs, just as thick terms, call into play speakers' moral values. 
accommodation and the fact that the pejorative content of slurs is nearly impossible to accommodate. We compare slurs to other presuppositiontriggers that exhibit the same hard-accommodation features, and we argue that cancellability should not be seen as a crucial diagnostic criterion for presupposition. We end the paper with a discussion of the objections against a presuppositional account of thick terms that have been put forward by Väyrynen (2013) and Kyle (2013).

\section{Disentangling the taxonomy maze}

Labels such as 'evaluative', 'expressive, 'normative', 'pejorative', 'slur','thick', 'thin' are often employed in metaethics, philosophy of language and linguistics, even though there is not much consensus about how to define these notions. In this section we propose a criterion to distinguish hybrid evaluatives from descriptive terms that can be used evaluatively (section 2.1). We also discuss the controversial thin-thick distinction and how it relates the distinction between at-issue vs. non-at-issue content, and we point out the difficulties of obtaining a clear-cut divide (section 2.2).

\subsection{Distinguishing hybrid evaluatives from descriptive terms that can}

\section{be used evaluatively}

The paradigmatic examples of thick terms are expressions such as 'lewd', 'generous', 'courageous', 'chaste', 'cruel'. The notion of a thick term has been first introduced in metaethics, and it is in the domain of metaethics that they have been mainly discussed (Williams (1985), Blackburn (1992), Gibbard (1992), among others.) The main characteristic of thick terms is that they combine descriptive meaning with evaluative meaning. The descriptive meaning can often be paraphrased: for example 'lewd' is descriptively equivalent to something like "sexually explicit"; 'generous', to something like "willing to give without expectation of compensation", 'chaste' to "abstaining from sexual intercourse", and so on. In addition to this descriptive content, 
when we apply a thick term to an object or individual, we also convey (or we express, as the case may be) a value-judgment about this object or individual. Thus to describe a person as 'lewd' typically implies something negative about the person, while to describe an act as 'generous' typically implies a positive evaluation of the act at stake. How the use of a thick term implies such an evaluation, and what kind of semantic and pragmatic mechanisms make it possible to express or convey such an evaluative content, are, of course, questions under debate.

Another class of terms that arguably mix description with evaluation and that have drawn the attention of philosophers and linguists in recent years are slurs. Slurs are derogatory terms targeting individuals and groups on the basis of their belonging to a certain category: they target sexual orientation (terms such as 'faggot', targeting homosexual men; or 'dyke', targeting homosexual women, etc.), nationality ('wop', targeting Italians; 'boche' targeting Germans, etc); ethnicity ('nigger' targeting black people, 'chink' targeting Asian people etc.) and so on. Again, the questions that these terms raise concern whether and how they encode evaluation, together with related issues such as: whether or not these terms can be used without being offensive (Brontsema 2004; Bianchi 2014; Croom 2014), whether or not they can be mentioned (Hornsby 2011; Anderson and Lepore 2013a, 2013b), whether or not they constitute a lexical category (Croom 2011, Nunberg 2015).

It is not always clear how to decide what counts as a slur or as a thick term and what doesn't. There has been some discussion whether terms such as 'athletic' should count as thick terms (see e.g. Eklund (2011): 37), and whether terms such as 'gypsy' should count as slurs. ${ }^{3}$ We propose the following criterion: in addition to a descriptive content, hybrid evaluatives systematically convey an evaluative content that scopes out when embedded under negation, conditionals, modals and questions. In section 3, we will see in greater detail

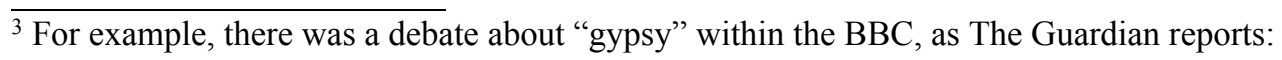
http://www.theguardian.com/media/organgrinder/2009/sep/24/gypsy-racist-ben-miller. 
that thick terms such as 'lewd' and slurs such as 'wop' pass the proposed criterion. This helps settling the issue whether a term like 'athletic' ought to count as evaluative: if we observe literal uses of the term that do not convey any evaluation at all, then the term should not count as a hybrid evaluative. And indeed, when one looks into the Corpus of Contemporary American English (a.k.a. COCA), one finds occurrences on which 'athletic' simply means "related to sports" as well as occurrences on which 'athletic' also appears to imply that being related to sports is a good thing:

1. In the Roman context, the heavy athletic disciplines were wrestling, boxing, and the pankration, a brutal blend of wrestling and boxing.

2. I wasn't a particularly athletic or popular child.

3. Everybody in cirque is athletic and handsome or beautiful.

The same goes for slurs: there are terms that have derogatory and nonderogatory occurrences, i.e. terms that work as slurs or not depending on the context. Here are some examples of the term 'gypsy' from COCA:

4. On the street, a violinist plays one of Bartk's Gypsy melodies. The vibrato from his violin feels as if it is penetrating my heart.

5. Calling that green-eyed minx a slut is too good for her. They say she's got Gypsy blood!

Even if one acknowledges that in (2)-(3) 'athletic' conveys a positive evaluation, in the way a thick term would, and that in (5) 'gypsy' appears to work like a slur, this is not a systematic and encoded feature of these terms, 
that is to say, the evaluative content is not (yet) built into the conventional meaning of these terms, as (1) and (4) show.

\subsection{Distinguishing thick terms from thin terms}

In the previous section, we have proposed a criterion that helps to distinguish hybrid evaluatives from ordinary descriptive terms that, in a suitable context, can be used evaluatively. A different question is how, among evaluative terms, one ought to distinguish between hybrid vs. pure evaluatives. In other words, how do we distinguish thick terms, such as 'courageous' or 'lewd', from thin terms, such as 'good' and 'bad'? The thin vs. thick distinction, which comes from metaethics (Williams 1985), is widely accepted, but not uncontroversial. Some major difficulties raised by this distinction are discussed in Väyrynen (2013), who defends the view that thick terms, or, more precisely, terms that are believed to be thick terms, such as 'courageous' or 'lewd', are really not any different from ordinary terms, and that the evaluations typically conveyed using such terms are generalized defeasible conversational implicatures. We, on the contrary, defend a view according to which those evaluations are recorded in the meaning of those terms, to the extent that the terms trigger presuppositions with evaluative content. Thus the question of what distinguishes pure evaluatives from hybrid evaluatives arises for our view.

One way of drawing the distinction would be to say that in the case of thin terms, evaluative content is at-issue content, while in the case of thick terms and slurs, evaluative content is presupposed, hence non-at-issue, while the descriptive content is at issue. ${ }^{4}$ Although we find the idea plausible to a certain extent, we suspect that the picture is more complicated than that. For one thing, it is easy to find uses of thin terms such that, because of the constructions in which they are used, their contribution does not reach into at-

\footnotetext{
${ }_{4}$ The distinction between at-issue vs. non-at-issue content is widely accepted in discourse
} analysis; see e.g. Roberts (1996), Potts (2005), Simons et al. (2010), Tonhauser (2012). 
issue content, but figures at the level of what is presupposed. Consider the following example. Two people have just watched Star Wars Episode 4:

6.

a) I missed the end of the movie cause I fell asleep. Who won at the end?

b) The good guys won.

In this example, it is part of the background who is good and who is bad; the thin term "good" does not convey any at-issue evaluation, but only serves to refer to Luke, Leia, Obiwan and Han Solo, rather than to Darth Vader.

For another thing, the evaluative content can become precisely what is at issue when using a hybrid evaluative. Consider:

7. Madonna's show was lewd. - I disagree. It was sexually explicit indeed, but it was not lewd.

We shall come back to this kind of case at greater length in section 3.2. For the time being, we would like to investigate more thoroughly the relationship between the thin and the thick. In the remainder of this section, we discuss examples that suggest that the divide between the thin and the thick is not as sharp as one might have thought. Then we postpone the discussion of the distinction until section 4 , in which we will look more closely at the semantics of different terms, thin and thick, in order to understand how they work and what the relevant differences are.

The difficulties for postulating a sharp boundary between the thin and the thick start as soon as we move from the basic, all-purpose evaluatives 'good' and 'bad' towards the wide range of terms that are typically used to convey evaluative content, do not appear to be descriptive, but are not devoid of any descriptive content either. Let us point out two kinds of case. 
First, consider the following two classes of expressions, the first one highly positive and the second one highly negative:

A. awesome, excellent, fantastic, formidable, magnificent, marvellous

B. abominable, awful, horrendous, horrible, outrageous, terrible

The task of deciding, for each among those expressions, whether it is thick or thin, is far from simple. On the one hand, we would want to say that the expressions in (A) all mean something like "good to a very high degree", and those in (B), "bad to a very high degree", which puts them on the thin side. On the other hand, there are differences in lexical meaning among the expressions in each class, and in general, some descriptive meaning seems to be available: e.g. 'awesome' is for what inspires awe (in a good way), 'excellent', is for what excels, 'abominable' is for what deserves to be loathed, and so on. The most reasonable position would be to say that the terms in (A) are thicker than 'good' and 'bad', but thinner than 'courageous' or 'cruel'.

Second, consider adjectives such as 'beautiful', 'ugly', or 'evil'. When discussed within the realm of aesthetics, 'beautiful' and 'ugly' are considered to be 'thin'. Similarly, 'evil', within the domain of ethics, would likely count as 'thin', as it means roughly the same thing as "morally bad". At the same time, from the broader perspective of looking at evaluative expressions in general, 'beautiful' and 'ugly' are narrower than 'good' and 'bad', as they constrains the evaluation to aesthetic evaluation, and 'evil' is narrower than 'bad', as the negative evaluation that it encodes is linguistically constrained to moral evaluation. The upshot is that the thin vs. thick divide need not be absolute. The descriptive content carried by the meaning of 'beautiful' tells us that the evaluation it conveys concerns aesthetic properties, but once restricted to the aesthetic discourse, there is no (or at least, does not seem to be any) further descriptive content that the adjective encodes. 


\section{The presuppositional account}

In this section we present a unified account of hybrid evaluatives in terms of presuppositions. In our analysis, hybrid evaluatives are expressions that are descriptive at the level of truth-conditions and trigger a certain kind of evaluative presupposition. We will observe some crucial features of hybrid evaluatives concerning the projection of the evaluative content (section 3.1) and the strategies employed to reject the descriptive and the evaluative content respectively (section 3.2); we will point out that the strategies of rejection reveal some interesting differences between descriptive and evaluative presuppositions.

\subsection{Projection}

A well-known feature of both thick terms and slurs is projection. ${ }^{5}$ Compare:

8. Madonna's show is lewd.

9. Madonna's show isn't lewd.

10. Is Madonna's show lewd?

11. If Madonna show is lewd, I wouldn't like to go.

12. Madonna's show might be lewd.

$\pi_{8}$. Things that are sexually explicit are bad, in some relevant respect, ${ }^{5}$ See, among others, Gibbard (1992), Jeshion (2013), Richard (2008), Väyrynen (2009; 2013). 
because of being so.

All the above occurrences of the term "lewd" seem to involve a negative evaluative content along the lines of $\pi_{8}$, even when the predicate is embedded under negation, questions, conditionals or modals. The same happens with slurs:

13. Madonna is a wop.

14. Madonna is not a wop.

15. Is Madonna a wop?

16. If Madonna is a wop, I don't wanna go to her concerts.

17. Madonna might be a wop.

$\pi_{13}$. Italians are worthy of contempt because of being so.

For both thick terms and slurs, we observe that the presupposed content triggered by hybrid evaluatives scopes out of semantic embeddings.

\subsection{Rejection}

In addition to the projective behavior described above, speakers cannot reject the evaluative content of hybrid evaluatives through mere denial ${ }^{6}$. Observe:

18.

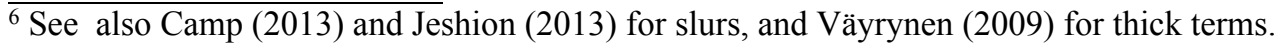


A: Madonna's show was lewd.

B1: No, it wasn't lewd.

B2: Well, the show was indeed sexually explicit, but there's nothing bad in this.

B3: Madonna's show wasn't lewd, because there is no such thing.

In the above exchange, the disagreement concerns the application of the predicate 'lewd' to a certain object, namely, Madonna's show: B1 acknowledges that there are things that are sexually explicit and bad because of it; however, according to B1, Madonna's show is not one of those things. $\mathrm{B} 2$ and $\mathrm{B} 3$, on the other hand, reject the idea itself that being sexually explicit can be bad in itself: B2 retrieves, articulates and rejects the presupposition triggered by A; B3 uses a metalinguistic negation. A similar case of metalinguistic rejection along the same lines of B3 comes from the trials of Oscar Wilde:

19.

Carson: Do you consider that ${ }^{7}$ blasphemous?

Oscar Wilde: "(...) the word 'blasphemous' is not a word of mine"

The same happens for slurs:

7 "That" refers to "The Priest and the Acolyt", a story from John Francis Bloxam.

${ }^{8}$ Passage from the trials of Oscar Wilde, see Foldy (1997), p.8. 
20.

A: Madonna is a wop.

B: No, she isn't.

B's answers in not really able to target the evaluation and it is at least ambiguous between denying the descriptive content and metalinguistically rejecting the evaluative content ${ }^{9}$. The issue of how to reject slurs in conversation is tricky and, unlike the case of thick terms, many social issues are at stake at the same time. Observe some examples of rejection of slurs from the COCA:

21.

A. I understand Black culture. I grew up around black people all my life. If the truth be told I probably know niggers better than you, Monsieur Delacroix.

B. I would prefer you not use that word in my presence.

22.

A. You think he's a fag.

B. You think he's gay.

23.

\footnotetext{
${ }^{9}$ Note that the metalinguistic reading is easier to access with some kind of follow up or with a marked intonation. 
A. I heard he was a fag $[\ldots]$

B. Historians don't generally put it quite that way, but yes, da Vinci was a homosexual.

In (21)-(23) speakers forbid or correct the use of a slurring term, but they don't articulate the presupposition properly. But we can find explicit articulations of the derogatory meaning of slurs in pedagogical contexts, where experts teach how to respond to slurs (homophobic, in the case at stake):

24. What you just said was really inappropriate because you are implying that there is something wrong with being gay or lesbian when there isn't. ${ }^{10}$

We observe that speakers tend not to articulate the presupposed content and we might wonder why. There are at least three factors to take into account:

(i) In general, to retrieve, explicitly articulate and reject a presupposition in a conversation is both cognitively and socially costly (see Chilton 2004: 64 ), so that simply rejecting the use of a term is easier for speakers rather than articulating the presupposition.

(ii) Slurs are prohibited words, whose use can also be prosecuted. ${ }^{11}$ This might explain why, in the case of slurs, people prefer a metalinguistic or silentistic solution, in order not to get involved with those terms: they tend to forbid the use of the term ("I would prefer you not use that word in my presence"), rather than explicitly articulating the presupposed content;

\footnotetext{
$10 \mathrm{http}$ //www.healthiersf.org/LGBTQ/InTheClassroom/docs/Responding\%20to $\% 20$ Homophobia.pdf.

${ }^{11} \mathrm{http}$ //fox2now.com/2015/10/06/missouri-company-faces-federal-lawsuit-over-racial-slurallegations/ 
nevertheless, as (24) shows, speakers are able to provide the relevant articulation if required.

(iii) There is a crucial difference between rejecting a descriptive and evaluative presupposition. Consider (25) and (27) and their presuppositions $\pi_{25}$ and $\pi_{27}$ :

25. Jane stopped smoking.

$\pi_{25}$. Jane used to smoke.

26. Hey wait a minute, I didn't know Jane used to smoke!

27. You finally realize you were dating a loser.

$\pi_{27}$. You were dating a loser.

28. * Hey wait a minute, I didn't know that I was dating a loser!

29. Hey you shouldn't talk like that about my ex.

Compare (25) and (27) and the presuppositions that they trigger: the presupposition conveyed by (25) only involves a state of affairs (someone using to smoke), whereas the one conveyed by (27) involves an evaluation about a someone (someone being a 'loser'). Now suppose that for each utterance, there is an interlocutor who does not take the presupposed content for granted and who is not willing to accommodate it immediately. In response to (25), a reply along the lines of "Hey wait a minute, I didn't know that...", as in (26), will be appropriate. Nevertheless, (28) shows that such answers are not appropriate anymore when an evaluation is at stake. If the speaker 
presupposes that someone is "a loser" and the interlocutor does not take that for granted, she cannot reply with something along the lines of "Hey, wait a minute, I didn't know that..."12.

The general point that we want to make is that when an interlocutor wants to reject a presupposed evaluation, the issue is not whether the interlocutor knew already the presupposed content or not, but rather whether she is willing to accept it or not. In general, when the presupposed content involves an evaluation, articulating the presupposition on the model of "Hey wait a minute, I didn't know that..." is not the best way to reject the presupposed content. As the above data suggest, the alternative strategies employed can include metalinguistic moves ((19), (21)); or corrections ((22)-(23)). The proper articulation and rejection of the evaluative presupposition is more likely to be found in pedagogical contexts, such as (24), and it does not involve "Hey wait a minute; I didn't know that..." kind of answers.

\section{An outline of the semantics of hybrid evaluatives}

In the previous sections, we have put forward a unified account of slurs and thick terms, which rests on the idea that both types of expressions encode a certain descriptive content and at the same time trigger an evaluative presupposition. For example, 'wop' roughly means 'Italian' but at the same time triggers the presupposition that Italians are bad because of being Italians; 'lewd' means "sexually explicit" and triggers the presupposition that things or individuals that are sexually explicit are bad because of being so; 'generous' means "disposed to give without expectation of receiving anything in return" and triggers the presupposition that those who are disposed to give without expectation of compensation are good because of that; 'disgusting' means "disposed to provoke disgust" and triggers the presupposition that things that

${ }^{12}$ Unless what is at stake is the interlocutor's knowledge regarding the speaker's belief, in which case answers such as "I didn't know you thought my ex is a loser" or "I didn't know you had such a bad opinion about my ex" sound appropriate. 
are disposed to provoke disgust are bad because of that; and so on. So far, however, we haven't said much about the associated evaluative content, nor have we explained what needs to be the case for such a content to hold. This is the aim of the present section, in which we start by outlining a semantics for the basic evaluative terms, namely 'good' and 'bad'. We shall see that such terms are highly context-sensitive and multidimensional: to decide whether the adjective 'good' applies to an object, event, or individual, a number of contextual factors need to be taken into account; the same goes for 'bad'. Relatedly, to decide whether the property picked out by the term 'good'/'bad' in a given context applies to a given object, event or individual, a number of different dimensions need to be taken into account. For example, consider the question whether some book is good. First, we contextually disambiguate 'good' into meaning something like "good as a book". Second, we pay attention to a variety of criteria that are plausibly relevant to deciding whether a book is good: is it good in terms of its writing style? originality? complexity of the plot? impact on the public? accuracy of content? and so on. The relevant dimensions themselves may vary from context to context, and there need not even be any agreement on which dimensions are relevant and which ones aren't. We shall see that this multidimensionality in meaning is also present, though to a lesser extent, in many adjectives that constitute thick terms, including 'lewd', 'generous' and 'disgusting'; on the other hand, slurs are not multidimensional in any analogous way. We will close the section by discussing the way in which this difference between thick terms and slurs affects the possible interpretations of the associated evaluative presuppositions.

\subsection{The semantics of 'good' and 'bad'}

The adjectives 'good' and 'bad' in English (and their equivalents in many other languages) are all-purpose evaluative adjectives. We speak of good 
weather, good cars, good meals, good results, good books, good movies, good actions, good souls. (Similarly with 'bad'). Our view is that on all these uses, 'good' and 'bad' are evaluative terms. But of course, at the same time, there are enormous differences among the evaluations that may be conveyed in those different cases. When we are judging a book or a movie to be good, we attribute to it a certain aesthetic value. When we are judging a person to have a good soul, or an action to be good, we attribute them a certain moral value. These sort of cases are the ones of greatest interest to philosophers. The other cases, such as the weather or cars, have not received much attention from philosophers, but they are not less evaluative for that reason. Importantly, the fact that the same word - 'good' - may be used to attribute all sorts of value (aesthetic, moral, functional, what not) does not mean that the word is ambiguous, nor that there is a special moral sense and a special aesthetic sense of 'good' (see Geach 1956). The differences in the kind of values that, in a given context, may be attributed by means of the all-purpose evaluative term 'good', are, in our view, contextually resolved.

The fact that the adjectives 'good' or 'bad' can combine with all sorts of noun phrases and, depending on the sort of thing to which they are applied, can point to different properties, has been noted for a long time, at least since Hare (1952) and Geach (1956). ${ }^{13}$ Even when good is applied to an individual, as in "Madonna is good", out of the context, the sentence might mean almost anything: that she is a good singer, that she is a good company, that she is a good businesswoman, that she a good mother, that she a good person, etc. Perhaps even more importantly, note that even when we restrict the interpretation, let's say to "good singer", or to "(morally) good person", there

\footnotetext{
${ }^{13}$ Geach (1956) and, in a more extensive and systematic way, Thompson (1992, 2003), are particularly keen on arguing that there isn't a single, monadic property of goodness in the moral realm. While we are sympathetic to their view, there is a way of interpreting the semantics of 'good' that we endorse here in a way that is compatible with moral monism. In this respect, our position remains neutral with respect to the metaethical debate in which Geach, Thompson and their opponents have been engaged.
} 
will still be several dimensions that, depending on the context, need to be taken into account for the attribution of goodness to hold. Thus a person may be (morally) good as regards treating others with respect, but not be so as regards helping out those who are in need. Or a singer may be good as regards the mastery of their voice, but not so with respect to the lyrics for their songs. This is what is commonly referred to as multidimensionality (see Bierwisch 1989 and, for more recent work, Sassoon 2013).

In addition to multidimensionality, all-purpose evaluative adjectives such as 'good' and 'bad' (but also a great number of thick terms, including 'generous' and 'disgusting') are gradable: some person may be better than some other; some actions may be very bad; others, scarcely bad. Gradability means that a property comes in degrees. Now, if a statement contains a gradable adjective, then in order to evaluate it for a truth value, first of all, we need to establish a scale. With multidimensional adjectives, the different dimensions contribute to establishing a single scale in ways which are still largely under-explored (for the complexity of the issue of how the different dimensions combine together to provide a single scale, see e.g. Glanzberg 2007, Sassoon 2013). Second, once such a scale is established, we need to fix a threshold on that scale (see e.g. Kennedy and McNally 2005, Kennedy 2007). Thus consider a case in which a person makes a $\$ 5$ donation to a charity, and suppose that we have determined the relevant scale of goodness. Then "That person's action is good" may still have different truth values in different contexts. In a context in which hardly anyone has made any donation at all, the threshold for a donation counting as a good action will be low, and the statement will be true. But in a context in which everyone has made a $\$ 500$ donation, and we know that the person at stake is rich enough to do the same, the threshold will be higher and the statement false.

To drive the point home, all-purpose evaluatives 'good' and 'bad' exhibit a very high degree of context-sensitivity (and the same goes for many other thin 
terms, such as 'great' or 'excellent'). Consequently, the evaluative presuppositions that we suggest are associated with hybrid evaluatives are also underspecified in meaning. Consider again our working examples, 'wop' and 'lewd'. They trigger respectively the presuppositions "bad because of being Italian" and "bad because of being sexually explicit". In both cases, the thin term 'bad' is semantically underspecified. Just as the context is crucial in figuring out the interpretation of a sentence in which a thin term figures, such as "Madonna is good", it is also required in making it possible to flesh out the evaluative presuppositions triggered by hybrid evaluatives. In section 4.3., we will see how the meaning of the hybrid evaluative itself may narrow down the possible interpretations, but in the meantime, let us take a look at how hybrid evaluative adjectives work at the descriptive level.

\subsection{The multidimensionality of thick terms}

We have stressed repeatedly that thick terms such as 'lewd' or 'generous' have meanings that combine two types of content: a descriptive content at the level of truth-conditions ("sexually explicit", "disposed to give without expectations of a compensation"), and an evaluative content at the level of presupposition. We have just seen that the evaluative component inherits context-sensitivity from the thin term that figures in the presupposition. But in addition, for many thick terms, the descriptive component, too, exhibits a high level of contextsensitivity. For one thing, it is most often the case that a thick term is gradable, ${ }^{14}$ and thus requires an associated scale, as well as a threshold on that scale. For another thing, how this scale is to be established is often, in turn, a context-sensitive matter. In other words, thick terms are very often multidimensional at the descriptive level as well. To see what this claim amounts to, let us first take a look at an example of a multidimensional term

${ }^{14}$ Or at least we speculate that it is so, based on the fact that the thick terms that are typically used in the literature are gradable: "lewd", "cruel”, "generous", "courageous", "brutal”, and so on. (On the other hand, "chaste" is not gradable.) 
that is descriptive but not evaluative. Consider the adjective 'simple'. Although the adjective may be used to convey something evaluative, neither a positive nor a negative evaluation is systematically associated with the use of the adjective, hence there is no evaluative presupposition associated with the adjective.

Following Sassoon (2013), a linguistic test that is used to check whether an adjective is multidimensional is to see whether it can be used felicitously with expressions such as “in \{all, most, three, some\} respects”. 'Good' and 'bad' clearly pass this test, and so do 'simple', 'lewd', and 'generous', whereas unidimensional adjectives such as 'tall' are infelicitous in such constructions:

30. Your task is simple in two respects: no time constrains and no budget limits!

31. The department party wasn't lewd in any respect.

32. She is generous in some respect; namely, in how she treats her guests.

33. \#Madonna isn't tall in any respect.

The semantics of 'simple' needs to make room for the respects, or ways, in which a thing (event, person) may count as simple. Thus to evaluate a sentence such as "This is simple" for a truth value, the context, apart from providing a referent $r$ for 'this', needs to provide a mapping from objects to degrees, a scale $S$ and a threshold $t$ on that scale, so that the sentence is true (as evaluated with respect to context $c$ and world $w)$, iff $\mathrm{d}(r) \geq t$, where $\mathrm{d}(r)$ is the degree to which $r$ is mapped. ${ }^{15}$ The dimensions of simplicity are taken into account at the level that, following Glanzberg (2007), can be called metasemantic. The basic idea is that context $c$ makes a number of dimensions ${ }^{15}$ Among theories of gradability, there are two approaches: one takes the context to supply a comparison class, and takes the latter to determine a threshold; the other (which we assume here for simplicity) takes the context to supply a threshold directly. The differences between the two approaches traditions need not concern us here. 
relevant, and distributes weights across those dimensions, which make it possible to establish a common scale relative to which things are assessed for simplicity. For example, consider the question of assessing whether a given task is simple, and whether task $\mathrm{A}$ is simpler than task B. One relevant dimension may be time constraints: suppose that the different segments of task A need to be accomplished in specific time intervals, but not so for B. Then B is simpler than A with respect to the time-constraints dimension. On the other hand, suppose that B requires connecting two sets of data in a logistically complicated way. Then B is less simple than A with respect to the logistic dimensions. Finally, the question of which between A and B is overall simpler may receive different answers, depending on whether more weight is put on the one dimension over the other.

The same sort of story generalizes to terms such as lewd, generous or disgusting. Bracketing for the moment the negative evaluation associated with lewd, how would we decide whether something or someone is lewd? Again, there is more than one way in which a thing, event or a person may be sexually explicit. Consider our earlier example, a certain show of Madonna's. One way in which it can be sexually explicit is by means of the way Madonna and her crew were dressed (e.g. sexy leather underwear). Another way in which it can be sexually explicit is by means of the behavior and the movements performed by them. Yet another way in which it can be sexually explicit is by eliciting explicit sexual behavior from the audience. Yet another way would be the sexual explicitness of the lyrics. These dimensions (and perhaps others that we haven't thought of) will combine, each contributing possibly a different weight in different context, to determine whether the descriptive content associated with 'lewd' holds of the event at stake or not. The descriptive content associated with 'generous' is multidimensional in a similar way: a person can be generous to others with money and material goods, they can be generous in terms of the time they devote to others, they 
can be generous in terms of their emotions or love, they can be generous in terms of the space they are willing to let the others have by detriment of their own space, and so on. Again, to decide whether someone is generous tout court, and whether a sentence of the form " $\mathrm{X}$ is generous" is true in a given context (assuming that the positive evaluation in the presupposition triggered holds), the context operates on these dimensions to establish a scale relative to which 'generous' is interpreted.

\subsection{Interpreting the evaluative presuppositions triggered by thick terms}

In this section, we discuss how the descriptive meaning of a thick term may constrain the interpretation of the associated evaluative presupposition. Let us present the general point by way of example, with two positive thick terms taken from different domains: 'generous', from the moral domain, and 'balanced', from the aesthetic domain. Their meanings are roughly: 'generous' := "willing to give without expectation of a compensation" + the presupposition that whatever or whoever is willing to give without expecting a compensation is good because of being so", and 'balanced':= "being in harmonious or proper arrangement, adjustment or proportion" + the presupposition that whatever or whoever is in harmonious or proper arrangement etc. is good because of being so." In both cases, the evaluative presupposition contains the all-purpose evaluative 'good', which is underspecified in meaning. We submit that the interpretation of the evaluative can vary with the context, but in ways which are partly constrained by the meaning of the thick term. Consider the following two:

34. The dancers' performance at last night's gala was balanced.

35. The dancers' donating all their profit from the gala to charity was generous (of them). 
(34) conveys that the artists' performance was good, and similarly, (35) conveys that the artists' donating their profit to charity was good. But of course, we understand that the two events were good in different ways: the performance was aesthetically good, and the act of donating to charity was morally good. We suggest that this difference in meaning derives from the properties that the two thick terms respectively refer to at the level of their descriptive content. Thus, in the context of (34), we may assume that the scale with respect to which 'balanced' is interpreted has been obtained by taking into account dimensions such as: arrangement among the different dance sequences, arrangement among the different dancers within each sequences, arrangement among the movements of each dancer, and so on. Being in harmonious arrangement, on any of those dimensions, is an aesthetic property. Thus "good because of being harmonious in arrangement" is implicitly enriched into something like "good with respect to arrangements of dance sequences, dancers, movements etc. because of being harmonious in arrangement". On the other hand, in the context of (35), the relevant dimension of interpreting 'generous' is the disposition to give their money to charity, which is (arguably) a property of the dancers qua agents in a society and, derivatively, qua moral agents. This is why the evaluation in the presupposition triggered is naturally interpreted as a moral evaluation.

It is important to keep in mind that neither in the case of 'generous' nor in the case of 'balanced' is the associated evaluation interpreted along the lines of "good in all moral respects because of being willing to give without expecting anything in return" or "good in all aesthetic respects because of being harmonious in arrangement." For there is no contradiction saying either of the following:

36. Their performance was balanced, but overall it was bad.

37. Sure they are generous, but in the end, they are bad persons. 
Instead, we should read the evaluative presuppositions along the lines of "good in this-and-that respect because of...", where the context helps figuring out which respects qualify as "this and that respect."

\subsection{The descriptive content of slurs}

We have discussed how the descriptive content narrows down the possible interpretation of the all-purpose evaluative ('good' or 'bad') that comes in the associated presupposition. Does anything similar happen in the case of slurs? Consider again our working example, the slur 'wop' that is used for Italians. The noun 'Italian' works differently from the adjectives that constitute thick terms. It can be said, quite unproblematically, that the noun 'Italian' denotes the set of (all and only) Italians. ${ }^{16}$ On the other hand, we have seen that with multidimensional adjectives such as 'good', 'bad', 'simple', 'generous' or 'lewd', a similar disquotational statement, e.g. “ 'simple' denotes the set of (all and only) simple things", does not make much sense. This is because 'simple' does not denote any monadic property, but is multiply relational: a thing is simple with respect to a dimension, a scale, a threshold, and so on. ${ }^{17}$ The same goes for most adjectives that belong among hybrid evaluatives.

One consequence of this is that the descriptive content of 'wop' (and similarly for other slurs) does not refer to any properties, as it only serves to

\footnotetext{
${ }_{16}$ We are considering here the noun 'Italian', used for members of a nation. The adjective 'Italian', as in "Italian architecture" or "Italian fashion" may be somewhat more vague. Also, there may be controversy regarding the criteria for being considered a member of a nation. ${ }^{17}$ The semantic structure of many among these adjectives is in fact even more complicated than that, for many among them come with implicit arguments. For example, a given task may be simple for one person and not so for another. The person for whom something is simple (similarly for 'painful', 'difficult', 'boring', etc.) is known, in the semantic literature, as the experiencer argument. The relationship between evaluativity and experiencer-sensitivity has been recently discussed in McNally and Stojanovic (2016). In addition, a number of the adjectives at stake arguably encode a beneficiary argument; in particular, the all-purpose evaluatives 'good' and 'bad' do so (on some of their usages): an event, for instance, may be good for one person and not so for another. How such implicit arguments interact with contextual parameters such as dimensions and thresholds are very complex metasemantic issues that have barely begun to draw attention.
} 
single out group membership, which means that this kind of descriptive content will be of little help in narrowing down the meaning of the all-purpose evaluative 'bad' that comes in the associated presupposition. In other words, in the evaluative presupposition "bad in this-and-that respect because of being Italian", the interpretation of "this and that respect" is hardly constrained at all. We think that this adequately captures the evaluative content that can be conveyed by a slur. In many cases, the slur will trigger the interpretation "bad in all (or most) respects because of being (...)" This, we think, is one of the reason why slurs are so strongly evaluative and thereby so pernicious.

In other cases, however, more specific interpretations are available. This availability way be due to the context or to the associated stereotype (or both), as illustrated by the following cases. Consider a context in which an enterprise is considering whether to hire Mr. Cutugno, who is Italian, as their public representative. If in such a context, someone makes the comment "Well, isn't he a wop?", they will likely convey the evaluative proposition that Italians (hence Mr. Cutugno as well) are bad with respect to duties such as being a public representative, and not necessarily that they are bad in every respect. Compare this with a case in which they are hiring a clerk, whose job merely requires being punctual and meticulous. In discussion the application of Ms. Kerner, a committee member raises a concern whether she would be have those qualities. If, in such a context, another member comments "Well, isn't she a boche?", then although they are still being derogatory about Germans, no negative evaluation seems to be conveyed regarding Ms. Kerner. To the contrary, the implicature is that Ms. Kerner will be punctual and meticulous, since these properties belong to the stereotype associated with the slur 'boche'.

Let us end the section by explaining how the presuppositional account that we have proposed sheds light on an issue that has been particularly problematic in the debate on both slurs and thick terms, namely, the issue of what these expressions refer to (see Richard (2008), Hom (2008), Hom \& May 
(2013) for slurs, Eklund (2011) for thick terms). In our analysis, slurs and thick terms have the same truth conditional content as their descriptive counterparts, but they fail to refer unless the evaluation conveyed in the presupposition holds. ${ }^{18}$ In this respect, slurs and objectionable thick terms are not any different from other presupposition triggers. Suppose that you see Madonna from distance and mistake her for a man. You might utter:

38. He is not very tall.

The pronoun 'he' comes with the presupposition that its referent is male. Given that this presupposition fails, two things follow: first, the occurrence of 'he' in (38) does not have a referent, and second, (38) does not have a truth value. Of course, we still understand, in a way, what (38) means, and if your interlocutor is aware of your mistake, they will likely correct you, e.g. by saying something like "You are right, she is not very tall" or "You are wrong: it's not a man, it's Madonna! But indeed, she is not very tall."

Turning back to hybrid evaluatives, if things that are sexually explicit are not bad - in the relevant respects - because of being so, then 'lewd' does not denote anything, and sentences in which it occurs lack truth value (unless the presupposition is suspended). Similarly, assuming that Italians are not bad because of being Italians, 'wop' is devoid of reference, and the corresponding sentences are devoid of truth value. This being said, competent speakers do understand the truth-conditional meaning of utterances where hybrid evaluatives occur, as well as the presupposed evaluation, but they will judge such utterances as true or false only if they share the evaluation conveyed. In order for a sentence in which a slur or a thick term occurs to be assessed for a truth value, the evaluative content in the presupposition triggered by the slur or the thick term must hold in the first place.

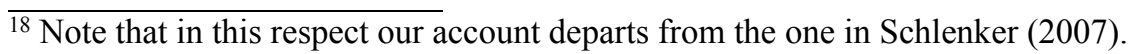




\section{Defending the presuppositional account}

In this section we will assess the main objections that have been raised against presuppositional accounts of slurs and of thick terms respectively. As far as slurs are concerned, the main objection involves the so-called 'cancellability', namely the possibility to prevent an embedded presupposition from projecting; in the case of thick terms, there are more general perplexities, among which we will triggering, appropriateness, negation-infelicity, and redundancy. We present these objections and argue that they do not pose any obstacles to our approach.

\subsection{Slurs and presuppositions}

The main objection that has been raised against a presuppositional analysis of slurs concerns the so-called 'cancellability' problem, namely the fact that presuppositions usually don't survive under certain embeddings. The prototypical case is the 'binding' one, when the antecedent of a conditional entails the content presupposed by the consequent; in such environments, the presupposition doesn't project. The case of slurs seems to be different under this respect. Compare:

39. Jane's sister must be smart.

$\pi_{39}$. Jane has a sister.

40. If Jane has a sister, Jane's sister must be smart.

41. Jane is a dyke.

$\pi_{41}$. Homosexual woman are bad because of being so.

42. ?? If homosexual woman are bad because of being so, Jane must be a dyke. 
Apart from its oddity, it is far from clear that (42) prevents $\left(\pi_{41}\right)$ from projecting. Whether one should consider this contrast between (39)-(40) and (41)-(42) as a knock-down argument against the presuppositional account of slurs depends on whether one should consider the so-called 'cancellability' as the crucial test for presuppositions. In what follows, we will argue that, independently from slurs, that is not the case. Our claim is that the ease of cancellation comes in degree, rather than being the distinctive feature of presupposition, and that many other factors come into play.

Ever since 'cancellability' was proposed as a diagnostic test for presuppositions, many authors (Karttunen (1971), Chierchia and McConnellGinet (1990), i.a.) have come up with problematic examples showing that the presuppositions of some triggers are very hard to neutralize.

One case is gender features of free pronouns; for example, "she" presupposes that the referent of the pronoun is female. Embedding the pronoun in a conditional doesn't neutralize the presupposition:

43. \# If John was female, she would be popular among boys. (Sudo 2012)

Likewise, most presuppositions are neutralized (they don't project), in certain disjunctions. For example (44) doesn't presuppose that Jane used to smoke:

44. Either Jane never smoked, or she stopped.

Nevertheless, such neutralizing effect doesn't work for gender features.

45. \#Either Jesse is a boy, or she hangs out with boys. (from Sudo 2012) 
At the same time, presuppositions triggered by slurs are not locally accommodated. Again, slurs share these features with gender features of free pronouns and particular triggers like "too".

46. ?? I am not sure whether Italians are contemptible. But if Leonardo is a wop, I'm sure he will understand some French.

47. ??I do not know her personally, because he is a man. (Sudo 2012) 48. ??I have no idea whether John read that proposal. But if Bill read it too, let's ask them to confer and simply give us a yes no response. (Abusch 2010).

The crucial point we want to make is that the fact that the evaluation conveyed by slurs always survives embedding and resist local accommodation does not discard the presuppositional analysis: as we saw, there are independent reasons to doubt that cancellability and suspendability are distinctive features of presuppositions in general. On the contrary, if such a presuppositional analysis of hybrid evaluatives is correct, it will constitute further evidence that challenges the cancellability and local accommodation requirements.

The hard neutralization of the evaluative component of slurs requires nevertheless an explanation: why is it so hard or nearly impossible to prevent the derogatory content of slurs from projecting in embedding contexts? One notion that could be helpful here is the soft/hard triggers distinction. According to some scholars (Abusch 2002, Abbott 2006, inter alia), we can distinguish soft and hard triggers, on the basis on how hard the presupposition they activate can be locally accommodated. ${ }^{19}$ According to Abusch (2002), who introduced this distinction, soft triggers introduce a pragmatic presupposition and hard triggers a semantic one. Leaving aside the whole

19 The distinction between hard and soft triggers is not uncontroversial, though. For a recent criticism, see Abrusán (2016). 
semantic/pragmatic debate on presupposition, we can take the distinction to amount to the following: some presuppositional triggers are more sensitive to context and extra-linguistic knowledge than others; this feature results in local accommodation being easier or harder. In the case of slurs, the presupposition always tends to project and survive semantic embedding.

Nevertheless, as Abrusán (2016) notices, things are way more complicated than that and many factors are called into play when it comes to local accommodation. Moreover, we should not neglect the fact that on top of all this, slurs bring about a taboo-effect that should not been underestimated. The fact that slurs are prohibited words could seriously affect our linguistic judgments in detecting projection; we expect such a taboo effect to be less salient, if not entirely absent, in the case of thick terms.

\subsection{Thick terms and presuppositions}

In this section, we will consider four worries voiced against the presuppositional account of thick terms, the first two from Väyrynen (2013) and the second two from Kyle (2013).

The first issue, the triggering problem, is that thick terms do not resemble any of the standard presuppositional triggers such as factive verbs, definite descriptions, cleft sentences etc. According to Väyrynen, it would be ad hoc to simply add new items to the list of presuppositional triggers. We believe that this worry is ill-grounded. Presupposition-triggers are not items that have been introduced as such to any natural language, in the way in which lists of items are stipulated e.g. for formal languages. It is only to be expected, from the way natural language works and evolves, that properties of expressions that have gone unnoticed by grammarians are brought to light. The evaluative dimension of language is one that, at least in the realm of formal linguistics, from which the notion of presupposition comes, has been under-invastigated. We thus fully embrace Väyrynen's point, though as one that scores in favor of 
our approach, rather than against it, that hybrid evaluatives are a brand new kind presupposition-triggers.

The second issue, the appropriateness problem, raised by Väyrynen has to do with the idea that presupposing is taking something for granted, assuming that the audience either does so as well or is ready to do so: "A cooperative speaker shouldn't presuppose something that is more properly put forward as a debatable assertion" (Väyrynen 2013, p. 113). Consider a conversation among 'lewd'-users and 'lewd'-objectors, namely people who respectively accept and refuse that things that are sexually explicit are bad because of that. Suppose that a 'lewd'-user uses the term 'lewd'. Since, by hypothesis, the evaluation is not already part of the background knowledge, given that it is rejected by the 'lewd'-objectors, it would be uncooperative of the speaker, i.e. inappropriate, to presuppose such an evaluation. As Väyrynen points out, the relevant scenario is the one where the speaker is fully aware that the audience (or part of it) doesn't share the presupposed evaluation. In these cases, we find it plausible to imagine that speakers do as if their evaluations were shared, and also that sometimes they impose them on purpose (expecting or not some kind of protest). In fact, in those scenarios, using a thick term whose evaluation is rejected by the majority of bystanders is indeed inappropriate. In a way, slurs themselves provide a crystal clear example of how inappropriate it is to presuppose an evaluation that is not shared by the participants to a conversation.

The third issue, the negation-infelicity problem, rests on the observation that sentences such as (49) below are highly infelicitous, and sound almost contradictory:

49. \# Nancy is generous, and she's not good in any way.

This example is from Kyle (2013) (his example nb. (5)), who uses it to 
argue for the kind of view he favors, on which thick terms semantically entail the evaluative content, and on which (49) is outright contradictory. But Kyle also thinks that the example is problematic for presuppositional accounts. As we saw in great detail in section 3.2., though, the infelicity of sentences such as (49) is actually predicted by presuppositional accounts such as ours, since denying a presupposition triggered by a preceding conjunct is infelicitous in general, as can be seen with any old case of presupposition-trigger:

50. \# Nancy stopped smoking, and she had never smoked.

But in fairness to Kyle, his worry against the presuppositional account consists to argue that (49) remains infelicitous even in contexts in which the presupposition is not the common ground among the conversation participants. He invites us to consider the following interchange (Kyle 2013: p. 11):

51.

$B o b$ : "Nancy is highly controlled in her giving and sharing, and that's what makes her fiscally smart. She is not generous. But she's not selfish either. I admire her approach to finances."

Sue: "I disagree with you, Bob. Nancy is generous, and she's not good in any way."

Kyle aims here to present a case in which Bob does not presuppose anything evaluative with his use of 'generous', so that no presupposition that being disposed to give without expecting anything in return (which is roughly the sort of evaluative content that we suggest is associated with 'generous') would be part of the common ground at the moment of Sue's utterance. He then concludes: "The context just described is one where those presuppositions are absent while the oddity of [(49)] remains. Thus, it's hard 
to see how an appeal to presupposition could explain the infelicity of sentences like (5)." (ibid.)

We think that Kyle's objection may affect at best those presuppositional accounts on which the evaluative presuppositions associated with thick terms are entirely construed as pragmatic presuppositions (see Stalnaker 1974). On our account, evaluative presuppositions are associated with thick terms in virtue of their lexical meaning. Thus even though Bob does not actively presuppose anything with his use of 'generous', this is not yet a reason good enough to claim that such a presupposition is not triggered but both his and Sue's use of 'generous'.

The fourth and last issue, the redundancy problem, rests on another observation made in Kyle (2013), who notes that sentences such as (52) below sound awkward:

52. ?Nancy is generous, and she is good in a way.

Again, Kyle uses this example to motivate his semantic view, based on the idea that stating something semantically entailed by the preceding conjunct is redundant, hence odd. But he also uses the example to argue against a close relative of the presuppositional approach, namely the conventional implicature approach. ${ }^{20}$ He suggests that conventional implicatures can be strengthened without giving rise to awkwardness, but that the evaluation conveyed by a thick term can't, hence that it does not pattern with conventional implicatures.

Let us see, though, whether this objection may affect our view nevertheless. Consider this repetition of the presupposition triggered by 'stop', which does

$\overline{20}$ In this paper, we have deliberately abstained from discussing the similarities and the differences between our presuppositional approach and an alternative conventional implicature approach, which has been defended, in the case of slurs, in McCready (2010) and Gutzman (2011). The distinction between presuppositions and conventional implicatures is a notoriously vexed issue. We believe that it does not affect the general gist of our proposal, and that entering the subtle technical details that supposedly distinguish the two phenomena would be more confusing than helpful for the reader. 
not appear to be redundant:

53. Nancy stopped smoking, and she (definitely) used to smoke!

For (53) to sound felicitous, we expect some stress on the presupposition, indicated here by 'definitely' and the exclamation mark. Can evaluative presuppositions be similarly made non redundant? We think that they can, and that the source of the oddity of (52) is, pace Kyle, primarily pragmatic. To see why, it will help to recall the discussion from section 4.4. There, we saw that the thick term contributes to narrowing down the possible interpretations of the implicit thin term in the presupposition. We also suggested that the presupposition triggered by 'generous' is to be read roughly along the lines of "good in this-and-that respect because of willing to give without expecting compensation." We further suggested that the properties relevant to interpreting the descriptive content of 'generous' provide some salient respects, which are used in interpreting the implicit "this-and-that respect". Having this in mind, we see the awkwardness of (52) as resulting from a clash between having some definite ways of being good that the term 'generous' raises to salience, and then following up with the indefinite "in $a$ way". And, as a matter of fact, if we use either a demonstrative or a contrastive construction instead, we get felicitous utterances:

54. Nancy is generous, and she is good in that way.

55. Nancy is generous, and she is good in other ways, too.

In sum, the two core observations that Kyle (2013) presents as motivations for the semantic account turn out to provide further support our account, rather than put it into jeopardy. 


\section{References}

Abbott, B. (2006), Where have some of the presuppositions gone, Drawing the boundaries of meaning: Neo-Gricean studies in pragmatics and semantics in honor of Laurence R. Horn, pp. 1-20.

Abrusán, M. (2016), Presupposition Cancellation: Explaining the Soft-Hard Distinction, to appear in Natural Language Semantics.

Abusch, D. (2002), Lexical alternatives as a source of pragmatic presuppositions, Semantics and Linguistic Theory, pp. 1-19.

Anderson, L. and Lepore, E. (2013a), Slurring Words, Nous, 47 (1), pp. $25-$ 48.

Anderson, L. and Lepore, E. (2013b), What did you call me? Slurs as prohibited words, Analytic Philosophy, 54 (3), pp. 350-363.

Bianchi, C. (2014), Slurs and Appropriation: an Echoic Account, Journal of Pragmatics, 66, pp. 35-44.

Bierwisch, M. (1989), The semantics of gradation, in Bierwisch, M. and Lang, E. (eds.), Dimensional Adjectives, Berlin, Springer-Verlag, pp. 71-261.

Blackburn, S. (1992), Through Thick and Thin, Proceedings of the Aristotelian Society, Supplementary Volumes, 66, pp. 285-299.

Brontsema, R. (2004), A queer revolution: reconceptualizing the debate over linguistic reclamation, Colorado Research in Linguistics, 17, pp. 1-17.

Camp, E. (2013), Slurring Perspectives, Analytic Philosophy, 54 (3), pp. 330349.

Chemla, E. and Schlenker, P. (2012), Incremental vs. symmetric accounts of presupposition projection: An experimental approach, Natural language semantics, 20 (2), pp. 177-226.

Chierchia, G. and McConnell-Ginet, S., (1990), Meaning and Grammar: an Introduction to Semantics, Cambridge (MA), MIT Press.

Chilton, P. (2004), Analysing Political Discourse: Theory and Practice, Routledge. 
Croom A. (2011), Slurs, Language Sciences, 33, pp. 343-358.

Croom A. (2014), Spanish slurs and stereotypes for Mexican-Americans in the USA: A context-sensitive account of derogation and appropriation, Sociocultural Pragmatics, 2, pp. 1-35.

Eklund, M. (2011), What are thick terms, Canadian Journal of Philosophy, 41 (1), pp. 25-49.

Eklund, M. (2013), Evaluative Language and Evaluative Reality, in S. Kirchin (ed.), Thick Concepts, Oxford, Oxford University Press.

Foldy, M. (1997), The Trials of Oscar Wilde, New Haven and London, Yale University Press.

Geach, P. (1956), Good and Evil, Analysis, 17(2), pp. 33 - 42.

Gibbard, A. (1992), Thick Concepts and Warrant For Feelings, Proceedings of the Aristotelian Society, Supplementary Volumes, 61, pp. 267-283.

Gibbard, A. (2003), Thinking How To Live, Cambridge (MA), Harvard University Press.

Gutzman, D. (2011), Expressive Modifiers \& Mixed Expressives, in Bonami, O. and Cabredo Hofherr, P. (eds.), Empirical Issues in Syntax and Semantics, 8, pp. 123-141.

Harcourt, E. and Thomas A., (2013), Thick Concepts, Analysis, and Reductionism, in Thick Concepts, Kirchin, S. (ed), Oxford, Oxford University Press, pp. 20-43.

Hare, R. M. (1952), The Language of Morals, Oxford, Oxford University Press.

Hornsby, J. (2001), Meaning and uselessness: how to think about derogatory words, Midwest Studies in Philosophy, 25, pp. 128-141.

Jeshion, R. (2013a), Expressivism and the Offensiveness of Slurs, Philosophical Perspectives, 27(1), pp. 231-259.

Jeshion, R. (2013b), Slurs and Stereotypes, Analytic Philosophy, 54(3), pp. 314-329. 
Karttunen, L. (1971), Some Observations on Factivity. Papers in Linguistics, 5, pp. 55-69.

Kennedy, C. (2007), Vagueness and grammar: The semantics of relative and absolute gradable adjectives, Linguistics \& Philosophy, 30, pp. 1-45.

Kennedy, C. and L. McNally, (2005), Scale structure, degree modification and the semantics of gradable predicates. Language 81:345-381.

Kyle, B. (2013), How Are Thick Terms Evaluative?, Philosophers'Imprint, 13(1), pp. 1-20.

McCready, E. (2010), Varieties of conventional implicature, Semantics and Pragmatics, 3(8), pp. 1-57.

McNally, L. and I. Stojanovic (2016), “Aesthetic Adjectives”, in Young, J. "The Semantics of Aesthetic Judgment", Oxford: OUP.

Nunberg, G. (2015), The Social Life of Slurs, forthcoming.

Roberts, C. (1996), Information Structure in Discourse: Towards an Integrated Formal Theory of Pragmatics, in Yoon, J. and Kathol, A. (eds.), Ohio State University Working Papers in Linguistics, 49, The Ohio State University Department of Linguistics, Columbus, Ohio, pp. 91-136.

Sassoon, G. W. (2013), A typology of multidimensional adjectives, Journal of Semantics, 30, pp. $335-380$.

Sibley, F. (1959), Aesthetic concepts, Philosophical Review, 68, pp. 421-450.

Simons, M., Tonhauser, J., Beaver, D. and Roberts, C. (2010), What projects and why, in Li, N. and Lutz, D. (eds.) (2010), Semantics and linguistic theory, (SALT) 20, Ithaca, NY, CLC Publications, pp. 309-327.

Stalnaker, R. (1974), Pragmatic Presuppositions, in Munitz and Unger (Eds.), Semantics and Philosophy, NY, New York University Press.

Sudo, Y. (2012), On the semantics of phi features on pronouns, dissertation, Massachusetts Institute of Technology.

Thomson, J. J. (1992), On Some Ways in Which A Thing Can be Good, Social Philosophy and Policy, 9 (2), pp. 96-117. 
Thomson, Judith Jarvis (2008), Normativity, Chicago, Open Court.

Tonhauser, J. (2012), Diagnosing (not-)at-issue content, In Proceedings of Semantics of Under-represented Languages of the Americas (SULA) 6, UMass, Amherst: GLSA, pp. 239-254.

Väyrynen, P. (2009), Objectionable Thick Concepts in Denials, Philosophical Perspectives, 23, pp. 439-69.

Väyrynen, P. (2011), Thick Concepts and Variability, Philosophers' Imprint, 11, pp. 1-17.

Väyrynen, P. (2013), The lewd, the rude and the nasty: A study of thick concepts in ethics, Oxford, Oxford University Press.

Williams, B. (1985), Ethics and the Limits of Philosophy, Cambridge (Mass), Harvard University Press.

Yablo, S. (2006), Non-catastrophic presupposition failure, Content and modality: Themes from the philosophy of Robert Stalnaker, pp. 164-190. 